\title{
Wear Modes of Contact Wire and Contact Strip under Electric Current Condition
}

\author{
Chikara YAMASHITA \\ Atsushi SUGAHARA \\ Current Collecting Maintenance Laboratory, Power Supply Technology Division
}

\begin{abstract}
To suggest measures for reducing wear of current collecting materials such as contact wires and contact strips, it is necessary to understand actual phenomena generated at the point of electric contact. For this study on classification of wear modes and transition conditions between hard drawn copper contact wire and iron-based sintered alloy contact strips, a linear wear testing method was newly introduced. As a result, it was found that the contact temperature which was estimated from the contact voltage depended on electric current and contact load. Consequently it was possible to classify wear modes of the current collecting materials under electric current conditions into three types depending on the maximum contact temperature.
\end{abstract}

Keywords: contact wire, contact strip, wear mode, linear wear test, contact temperature, melting point

\section{Introduction}

In order to supply high power to an electric vehicle, current collecting materials such as catenary contact wires and pantograph contact strips are subjected to sliding contact under high electric current conditions for various loads and speeds. This causes complex wear of current collecting materials making inspection of the wear and the replacement of the materials extremely time consuming and difficult. In recent years, there has been a growing need for further measures to reduce the wear of current collecting materials because of increased wear due to higher current intensity of use and greater vehicle speed.

Wear modes of current collecting materials were empirically classified into mechanical wear and electrical wear modes. The mechanical wear mode is thought to be caused by adhesive and abrasive wear under high contact load conditions, whereas the electrical wear mode is thought to be caused by electric arcs under contact loss conditions. According to previous studies [1, 2], the wear rate of current collecting materials increases significantly due to electric arcs. Wear reduction measures have therefore been proposed to prevent contact loss by improving dynamic interaction between the catenary and the pantograph. Some field measurements [3] however, indicate that the wear rate of the contact wire at points where electric arcing recurs is significantly small. Thus, based on these results alone it is not possible to confirm that the wear mechanism in electrical wear mode can be explained solely by electric arcing. In order to suggest measures for reducing the wear of current collecting materials, it is essential to elucidate the wear mechanisms under electric current conditions. This study describes new wear test apparatus which was developed and used to carry out wear tests to classify the wear modes of current collecting materials under electric current conditions and to clarify the transition conditions between the wear modes.

\section{Experimental method}

\subsection{Wear test apparatus}

Conventionally, in order to evaluate wear properties of current collecting materials, some large rotary type wear test apparatus are produced which can simulate actual driving conditions, especially at high speed. However, since contact load fluctuation is significant with rotary wear test apparatus, the wear surface after the wear test shows a mixture of various wear modes. This study points out that this mixture of wear modes is one of the factors inhibiting the classification of wear modes and the clarification of wear mechanisms under electric current conditions. This study examines the wear test method in the manner described below to determine the influence of electric current and load on wear properties of the contact wire and the contact strip.

(1) Reduce contact load fluctuation during sliding to prevent mixing of wear modes.

(2) Provide a certain amount of friction interval to reproduce thermal effects on the contact wire which are close to real conditions.

(3) Carry out wear tests at low sliding speed to reduce frictional heat.

(4) Measure contact voltage precisely to estimate the state of contact between the contact wire and the contact strip.

As a result of consideration of these factors, a liner type wear test apparatus was developed, as shown in Fig. 1. By setting a slower sliding speed, the standard deviation of the contact load was less than $6 \%$. Furthermore, there was no need for a slip ring which is a source of noise in this linear wear test apparatus, thus the contact voltage measurement accuracy was improved. 


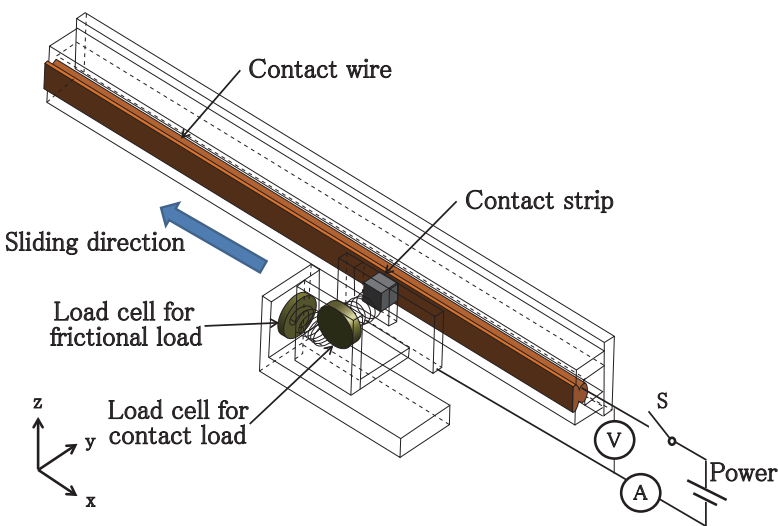

Fig. 1 Schematic diagram of the linear wear test apparatus

\subsection{Wear test conditions}

The wear test conditions are shown in Table 1 . The test materials, namely hard-drawn copper contact wire and an iron-based sintered alloy contact strip are commonly used on electrified railway lines in Japan. The reason for choosing the iron-based sintered alloy for the contact strip was to facilitate the determination of the transferred material by using the EPMA (Electron Probe Microanalyser). The physical properties of the test materials are shown in Table 2. A contact load in the range of $2-80 \mathrm{~N}$ was applied to avoid the occurrence of large arcing and seizure. A sliding speed of $0.2 \mathrm{~m} / \mathrm{s}$ was applied to reduce contact load fluctuation and frictional heat. A friction interval of about 5 seconds was applied during the wear test corresponding to the intervals of the pantograph passing on a real train, if there are multiple pantographs on a vehicle.

Since the width of the contact strip specimen is smaller than that of the contact wire specimen, part of the contact wire surface is not exposed to wear. This unworn surface is used to measure the surface profile before and after the wear test as shown in Fig. 2 and to calculate the wear area in the cross section of the contact wire. The wear rate of the contact wire $W_{s t}\left[\mathrm{~mm}^{2} / \mathrm{N} \cdot\right.$ cycle $]$ is calculated by the following equation,

$$
W_{s t}=\frac{A}{P \cdot N}
$$

where, $A$ is the wear area in the cross section of the contact wire $\left[\mathrm{mm}^{2}\right] ; P$, the contact load $[\mathrm{N}]$; and $N$, the number of friction cycles. The specific wear rate of the contact strip $W_{s s}\left[\mathrm{~mm}^{3} / \mathrm{N} \cdot \mathrm{m}\right]$ is calculated by the following equation,

$$
W_{s s}=\frac{\Delta m}{\rho \cdot P \cdot L}
$$

where, $\Delta m$ is the decrease in mass of the contact strip during the wear test $[\mathrm{g}] ; \rho$, the mass density of the contact strip $\left[\mathrm{g} / \mathrm{mm}^{3}\right]$; and $L$, the total sliding distance of the contact strip [m].
Table 1 Wear test conditions

\begin{tabular}{l|l}
\hline Contact wire & Hard-drawn copper \\
\hline Contact strip & Iron-based sintered alloy \\
\hline Contact load $[\mathrm{N}]$ & $2 \sim 80$ \\
\hline Sliding speed $[\mathrm{m} / \mathrm{s}]$ & 0.2 \\
\hline Voltage $[\mathrm{V}]$ & $\mathrm{DC} 0,100$ \\
\hline Electric current $[\mathrm{A}]$ & $0,50,80,100$ \\
\hline Sliding distance $[\mathrm{mm}]$ & 250 \\
\hline Sliding cycle & 3,000 \\
\hline Friction interval $[\mathrm{sec}]$ & Approximately 5.0 \\
\hline
\end{tabular}

Table 2 Physical properties of test materials

\begin{tabular}{c|c|c}
\hline & Contact wire & Contact strip \\
\hline Components & $\mathrm{Cu}(99.9 \%)$ & $\begin{array}{c}\text { Fe }(78.6 \%), \\
\mathrm{Cr}(16.5 \%), \\
\mathrm{S}(0.9 \%)\end{array}$ \\
\hline $\begin{array}{c}\text { Mass density } \\
{\left[\mathrm{g} / \mathrm{mm}^{3}\right]}\end{array}$ & $8.91 \times 10^{-3}$ & $7.10 \times 10^{-3}$ \\
\hline Resistivity $[\mu \Omega \mathrm{m}]$ & $1.77 \times 10^{-2}$ & 0.40 \\
\hline $\begin{array}{c}\text { Heat conductivity } \\
{[\mathrm{W} / \mathrm{mK}]}\end{array}$ & 373.0 & 25.3 \\
\hline $\begin{array}{c}\text { Specific heat } \\
{[\mathrm{J} / \mathrm{kgK}]}\end{array}$ & 381 & 485 \\
\hline Melting point $[\mathrm{K}]$ & 1,334 & 1,646 \\
\hline \multicolumn{2}{|l}{}
\end{tabular}

$$
\text { - after test } \quad-.- \text { - before test }
$$

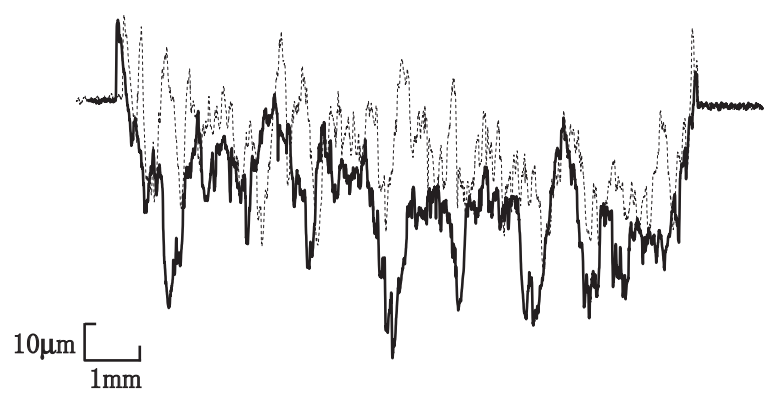

Fig. 2 Cross sectional profiles of the contact wire

\section{Wear test results}

Figures 3-5 show the relationship between the contact load and the wear properties (the wear rate of the contact wire, the specific wear rate of the contact strip and the friction coefficient) under four electric current conditions $(0$, $50,80,100 \mathrm{~A})$. In these figures, it is possible to see that the wear properties when there is no current remain almost unchanged throughout the load variation. According to Fig. 6 of the SEM (Scanning Electron Microscope) images of the wear surfaces under non-current conditions, shearing traces are observed on both surfaces. Therefore, the wear mode observed under non-current conditions could be classified as a mechanical wear mode alongside adhesion wear and delamination. 


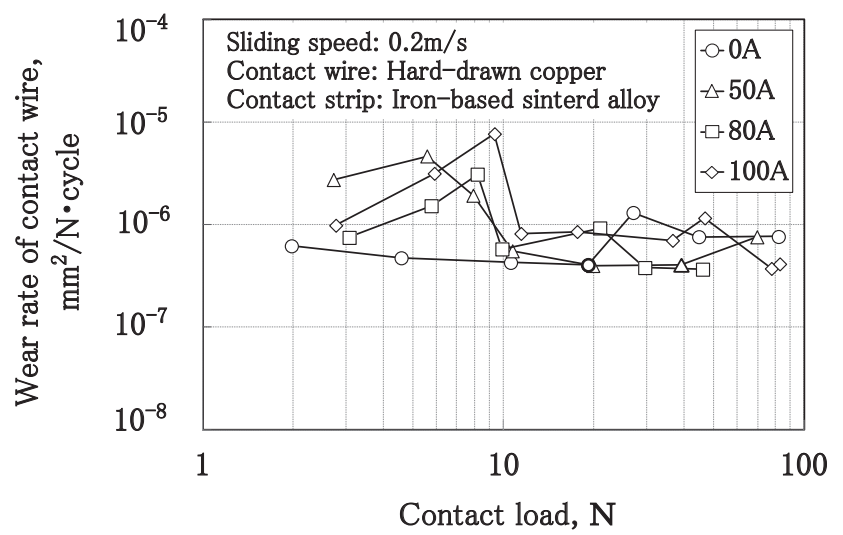

Fig. 3 Relationship between the contact load and the wear rate of the contact wire

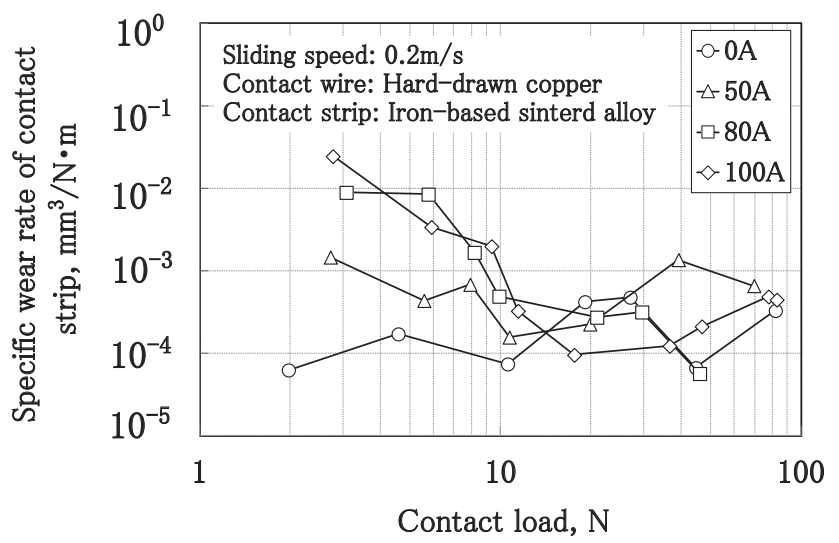

Fig. 4 Relationship between the contact load and the specific wear rate of the contact strip

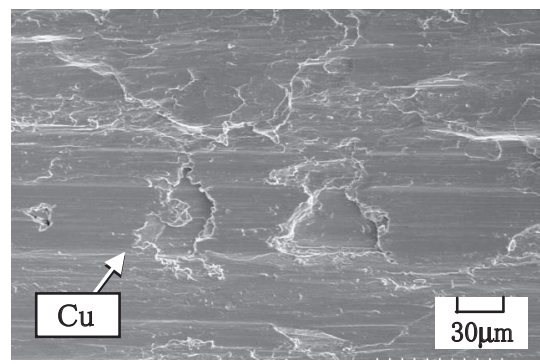

(a) Contact wire
Wear properties under electric current conditions however can be classified into three types as follows.

(1) According to Figs. 3-5, the wear properties beyond 10 $\mathrm{N}$ under current conditions are similar to the values obtained with no current. Under the latter load conditions, the wear surfaces of the contact wire and the contact strip are also the same as in Fig. 6, and no traces of melting were observed. From these results it can be said that if the load is fully applied, the influence of the electric current on the wear properties is negligible even under current conditions and the wear mode becomes mechanical.

(2) According to Figs. 3 and 5, the maximum values of the wear rate of the contact wire and the friction coefficient are observed for 6-10 N under electric current conditions. Under these load conditions, traces

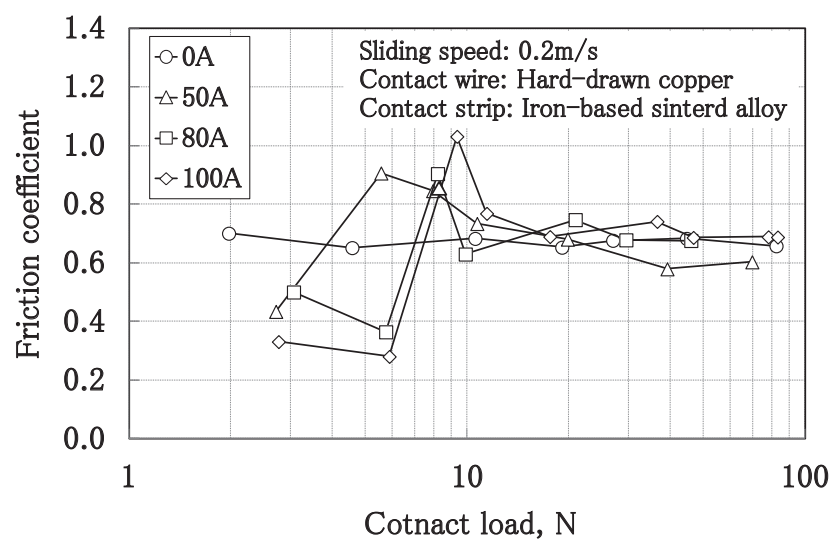

Fig. 5 Relationship between the contact load and the friction coefficient

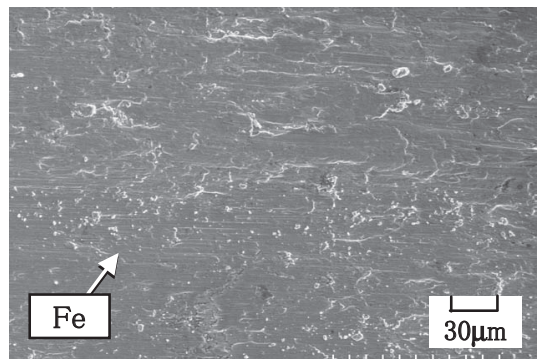

(b) Contact strip

Fig. 6 SEM images of the wear surface (contact load: $27 \mathrm{~N}$, sliding speed: $0.2 \mathrm{~m} / \mathrm{s}$, electric current: 0 A)

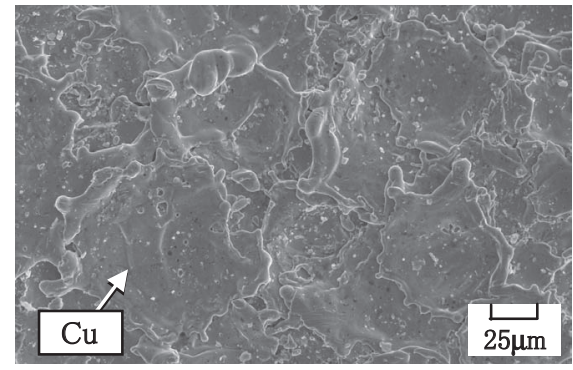

(a) Contact wire

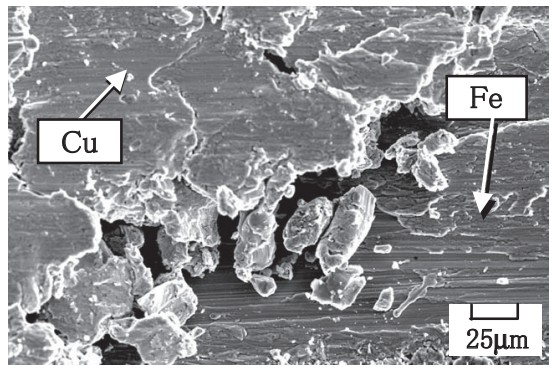

(b) Contact strip

Fig. 7 SEM images of the wear surface

(contact load: $9.3 \mathrm{~N}$, sliding speed: $0.2 \mathrm{~m} / \mathrm{s}$, electric current: $100 \mathrm{~A}$ ) 


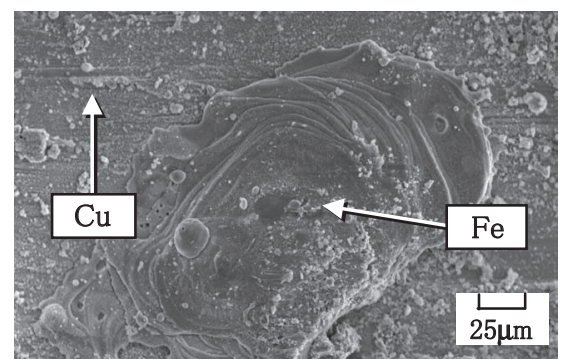

(a) Contact wire

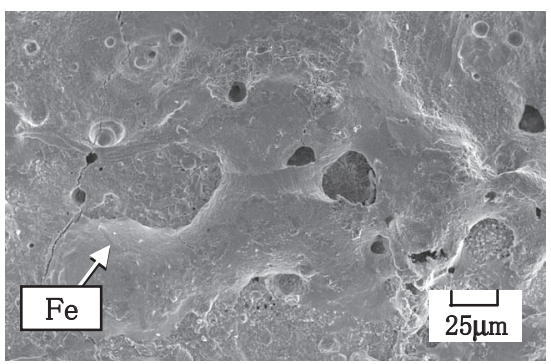

(b) Contact strip

Fig. 8 SEM images of the wear surface (contact load: $2.7 \mathrm{~N}$, sliding speed: $0.2 \mathrm{~m} / \mathrm{s}$, electric current: $100 \mathrm{~A}$ )

of melting copper, which is a main component of the contact wire, is observed on the contact wire surface. Melted copper debris is deposited on the contact strip surface as shown in Fig. 7. It should be noted that there is no melting iron on the surface of the contact strip. This was called electrical wear mode I because it provides insight into the influence of the current on the wear properties.

(3) According to Fig. 4, the values of specific wear rates of the contact strip with a load of less than $6 \mathrm{~N}$ under current conditions, increase significantly. Under these load conditions, the friction coefficient under electric current conditions falls below that found under noncurrent conditions as shown in Fig. 5, and the wear rate of the contact wire under electric current conditions decreases as the contact load is reduced, as shown in Fig. 3. On the wear surfaces shown in Fig. 8, traces of melted iron, which is a main component of the contact strip, can be seen on the contact strip surface. Melted iron debris is deposited on the contact wire surface. It should be noted that there is no melted copper on the contact wire surface. This was called electrical wear mode II because it provides insight into other influences of the current on the wear properties.

In previous studies, it was believed that the wear rate of the contact wire significantly increased with electric arcing, the present wear tests demonstrated that this was not the case. Results illustrated the fact that the wear rate of the contact wire at the point where electric arcing recurred was very small.

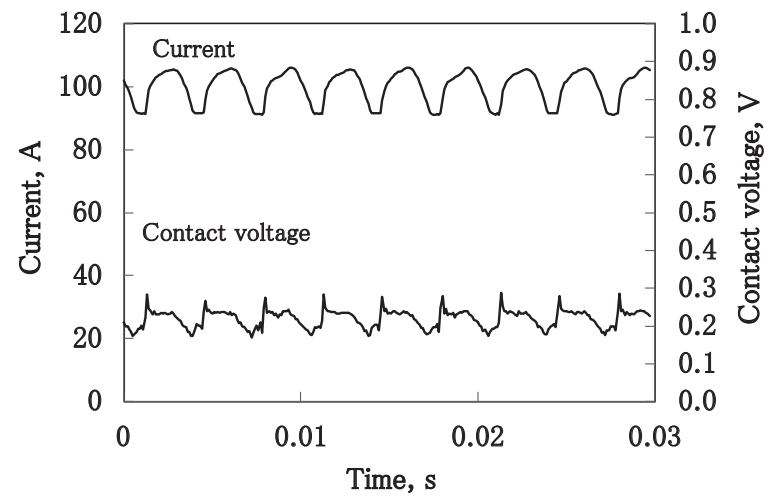

(a) Stationary (speed: $0 \mathrm{~m} / \mathrm{s}$ )

\section{Discussion}

This chapter discusses the transition conditions between wear modes by considering the contact temperature and the melting point of the current collecting materials. Although it is difficult to measure the contact temperature directly, there is " $\varphi-\theta$ Theory" proposed by R. HOLM [4] for estimating the maximum contact temperature $T_{\max }[\mathrm{K}]$ from the contact voltage $V_{c}[\mathrm{~V}]$ by the following equation,

$$
T_{\max }=\left(\frac{V_{c}^{2}}{4 L}+T_{0}^{2}\right)^{1 / 2}
$$

where, $L$ is the Lorentz number $\left(=2.4 \times 10^{-8}\right)$; and $T_{0}$, the room temperature ( $=300 \mathrm{~K})$.

Figures 9 (a), (b) show the measured waveform of the current and contact voltage under stationary and sliding conditions. According to Fig. 9 (a), the waveform of the contact voltage is a ripple form which is naturally caused by rectification. In other words, there is little noise in the contact voltage when stationary. Since the linear wear test apparatus can measure the contact voltage precisely as described in Section 2.2, the influence of the small fluctuation of the contact load and the number of the contact spots during sliding would appear in the waveform of the contact voltage as shown in Fig. 9 (b). Joule heat and rising temperature at the contact spots was so fast that the statistic maximum contact voltage $V_{\max }[\mathrm{V}]$ was evaluated using the following equation,

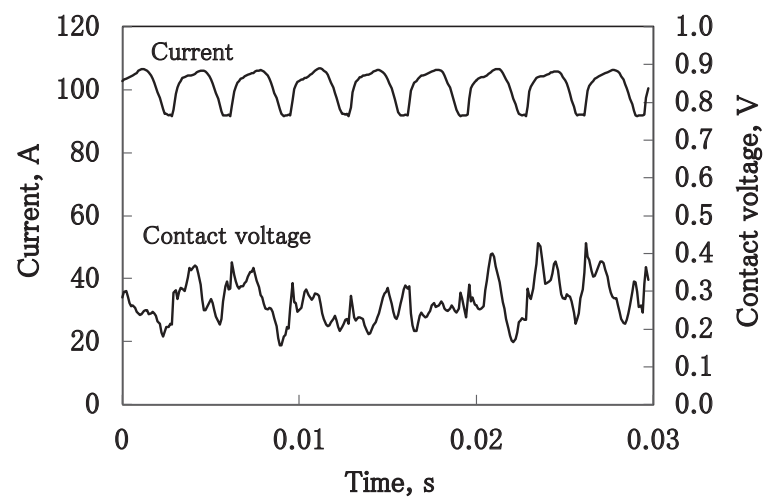

(b) Sliding (speed: $0.2 \mathrm{~m} / \mathrm{s}$ )

Fig. 9 Measured waveform of current and contact voltage (Current: $100 \mathrm{~A}$ ) 


$$
V_{\max }=V_{a}+3 \sigma
$$

where, $V_{\mathrm{a}}$ is the average value of the contact voltage [V], and $\sigma$, the standard deviation of the contact voltage [V]. Furthermore, since the influence of heat from friction on the contact temperature could be negligible at low sliding speed, the maximum temperature can be calculated by (3). Figure 10 shows the relationship between the contact load and the statistic maximum contact voltage under three electric current conditions $(50,80,100 \mathrm{~A})$. In this figure, it is possible to see that the statistic maximum contact voltage increases with the increase of electric current and the decrease in contact load.

Figure 11 shows the contour graph of the maximum temperature at the contact spot calculated with equation (3) and the statistic maximum contact voltage measured in Fig. 10. For this calculation, the contact temperature under non-current conditions was assumed to be $300 \mathrm{~K}$. In addition, the classification of wear modes for each wear test condition is plotted in Fig. 11.

From this figure, it was clear that the transition condition between the mechanical wear mode and the electrical wear mode I coincided approximately with the condition under which the contact temperature reaches the melting point of the contact wire, $1,334 \mathrm{~K}$. In other words, the wear mode transition from the mechanical wear mode to

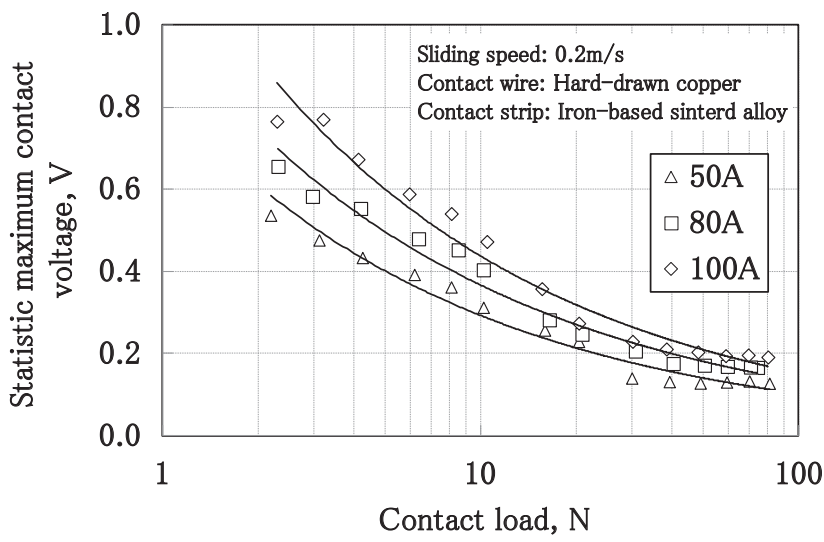

Fig. 10 Relationship between contact load and statistic maximum contact voltage

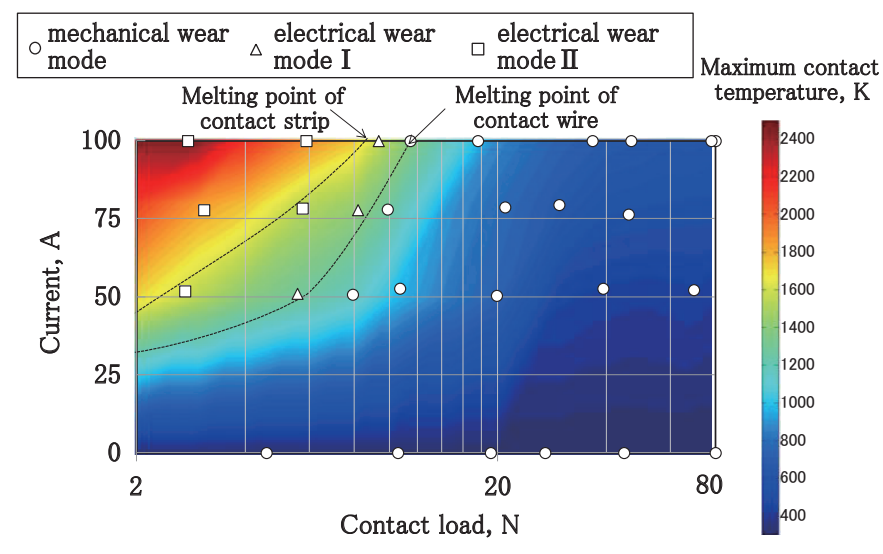

Fig. 11 Relationship between wear mode and maximum contact temperature

the electrical wear mode I occurred because of the melting of the contact wire. The contact temperature should rise enough to soften the contact wire surface even with mechanical wear under electric current conditions, however, there was no observation of the influence of material softening on the wear mode transition and the wear properties. It was also found that the transition condition between the electrical wear mode I and the electrical wear mode II coincided approximately with the condition under which the contact temperature reached the melting point of the contact strip, $1,646 \mathrm{~K}$. In other words, the wear mode transition from the electrical wear mode I to the electrical wear mode II occurred because of the melting of the contact strip.

From this discussion, the wear process of the current collecting materials and the wear modes could be explained as follows with the contact model shown in Fig. 12.

(1) Since contact resistance is sufficiently small under high contact load conditions, the maximum contact temperature is below $1,334 \mathrm{~K}$ which is the melting point of the contact wire and both materials do not melt as shown in Fig. 12 (a). The wear mode then becomes mechanical wear whereby influence of electric current on wear properties can be ignored.

(2) The contact voltage and the maximum contact temperature increase due to reduction of the contact load.

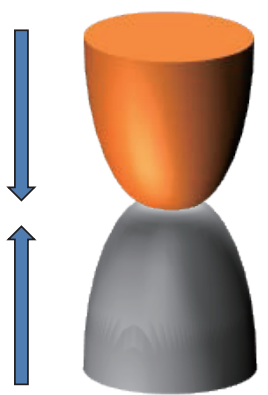

(a) No melting

(Mechanical wear mode)

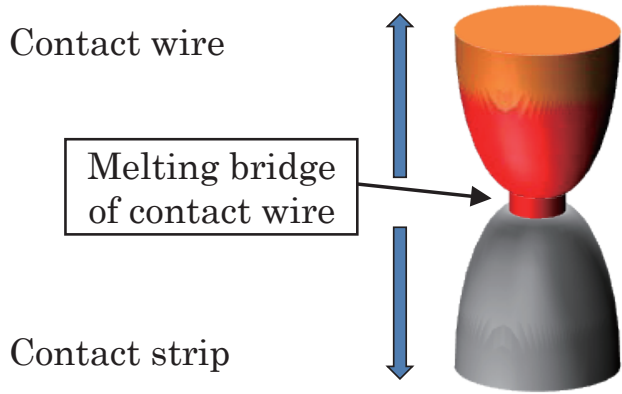

(b) Melting bridge of contact wire

(Electrical wear mode I)

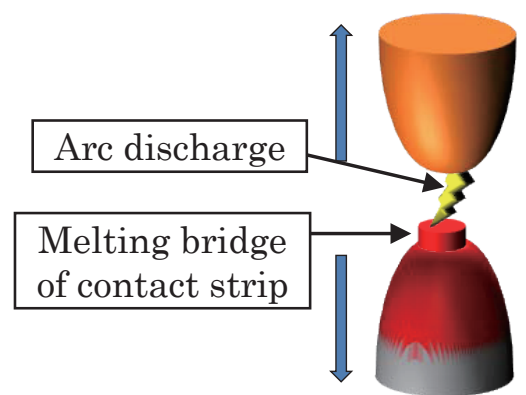

(c) Melting bridge of contact strip and arc discharge

(Electrical wear mode II)

Fig. 12 Wear process of current collecting materials under electric current conditions 
Since the melting point of the contact wire is lower than that of the contact strip, the melting bridge on the contact wire is formed before the contact strip melts, as shown in Fig. 12 (b). The wear mode then becomes electrical wear I and the wear rate of the contact wire increases significantly.

(3) If the contact temperature rises beyond the melting point of the contact strip, the melting bridge of the contact strip is formed and arc discharge occurs as shown in Fig. 12 (c). The wear mode then becomes electrical wear II and the wear rate of the contact strip increases significantly. The maximum contact temperature also exceeds the melting point of the contact wire, however, there is no melting contact surface in this wear mode.

\section{Conclusions}

The authors introduced a new linear wear test apparatus and found that friction and wear properties of the current collecting materials under electric current conditions can be classified into three types as follows on the basis of the maximum contact temperature.

(1) When the contact temperature is lower than the melting points of the contact wire and the contact strip; The friction coefficient and the wear rate under electric current conditions are similar to those under noncurrent conditions.
(2) When the contact temperature is higher than the melting point of the contact wire and lower than that of the contact strip;

The surface of the contact wire melts, and the friction coefficient and the wear rate of the contact wire increase significantly.

(3) When the contact temperature is higher than the melting point of the contact strip;

The surface of the contact strip melts, and the friction coefficient and the wear rate of the contact wire fall, and the wear rate of the strip increases significantly.

\section{References}

[1] Kohno, A., Ohyabu, H. and Soda N., "Effect of Discontact Arc on Wear of Materials for Current Collection (Part 1) ," Journal of Japan Society of Lubrication Engineers, Vol. 27, No. 4, pp. 283-287, 1982 (in Japanese).

[2] Kohno, A., Ohyabu, H. and Soda N., "Effect of Discontact Arc on Wear of Materials for Current Collection (Part 2) ," Journal of Japan Society of Lubrication Engineers, Vol. 27, No, 7, pp. 527-532, 1982 (in Japanese).

[3] Iwase, M., "Current Collecting by the Pantograph and its Wear (II)," Railway Technical Research Report, Vol. 217, 1961 (in Japanese).

[4] Holm, R., Electric Contacts Theory and Applications, $4^{\text {th }}$ ed., $§ 13,1967$.

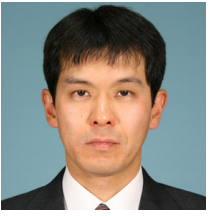

Atsushi SUGAHARA

Laboratory Head, Current Collecting

Maintenance Laboratory, Power Supply

Technology Division

Research Areas: Over Head Line Materials 